\title{
Radionuclide entrainment coefficients by wash-off derived from plot experiments near Chernobyl
}

\author{
L. Garcia-Sanchez ${ }^{1}$, A. Konoplev² and A. Bulgakov ${ }^{2}$ \\ ${ }^{1}$ IRSN, Environmental Modelling Laboratory, 13115 Saint Paul-lez-Durance, France \\ ${ }^{2}$ SPA "Typhoon", Centre for Environmental Chemistry, Obninsk 249039, Russia
}

\begin{abstract}
This work aimed at treating the new database on cesium-137 and strontium-90 transfer by wash-off collected by IRSN in the framework of the Franco-German Initiative for Chernobyl. It focused on the 71 runoff plot (from 1 to $400 \mathrm{~m}^{2}$ ) experiments conducted under artificial rainfalls in the Chernobyl district between 1986 and 1998. These data, mostly still unpublished, provide a quantification of wash-off at the rainfall scale, still rare for radionuclides. Normalized entrainment coefficients by liquid and solid wash-off were calculated for each experiment. In average, the liquid entrainment coefficient was $10^{-5} \mathrm{~mm}^{-1}$ for cesium, and $10^{-3.8} \mathrm{~mm}^{-1}$ for strontium. The solid entrainment coefficient was $10^{-41} \mathrm{~m}^{2} \mathrm{~g}^{-1}$ for cesium and $10^{-4.3} \mathrm{~m}^{2} \mathrm{~g}^{-1}$ for strontium. These trends and values were found consistent with reported values in the literature. For assessment purposes, the extrapolation of these coefficients to wider areas and to other sites would need their physical interpretation.
\end{abstract}

\section{INTRODUCTION}

After an atmospheric deposition, radionuclide wash-off from watersheds can be an important and persistent supply to water bodies because it collects fluxes from wide contaminated areas that remain affected by precipitations [1].

Wash-off has been mainly studied at large time and spatial scales by using the notion of transfer function. With this paradigm, watersheds are supposed to have a linear wash-off response to atmospheric deposition. This approach assumes that the time-dependent wash-off averaged over a season or a year- is proportional to the deposited amount (proportionality principle) and adds up the responses to individual deposition events (superposition principle). The characteristic wash-off response of a given watershed to a single unit deposit is called its transfer function. Many analytical formulations of the transfer function have been proposed for the bombogenic [2] and Chernobyl fallout [3-5], with their estimated parameters.

The authors would like to thank Gerard Deville-Cavelin (IRSN) and Viktor Chabanyuk (Geo Ltd, Ukraine) for managing the releases of the FGI "Runoff" database and satisfying our requests. The existing data could be collected thanks to the collaboration Oleg Voitsekhovitch (UHMI, Ukraine) and Olga Zhukova (RCRCM, Belarus). 


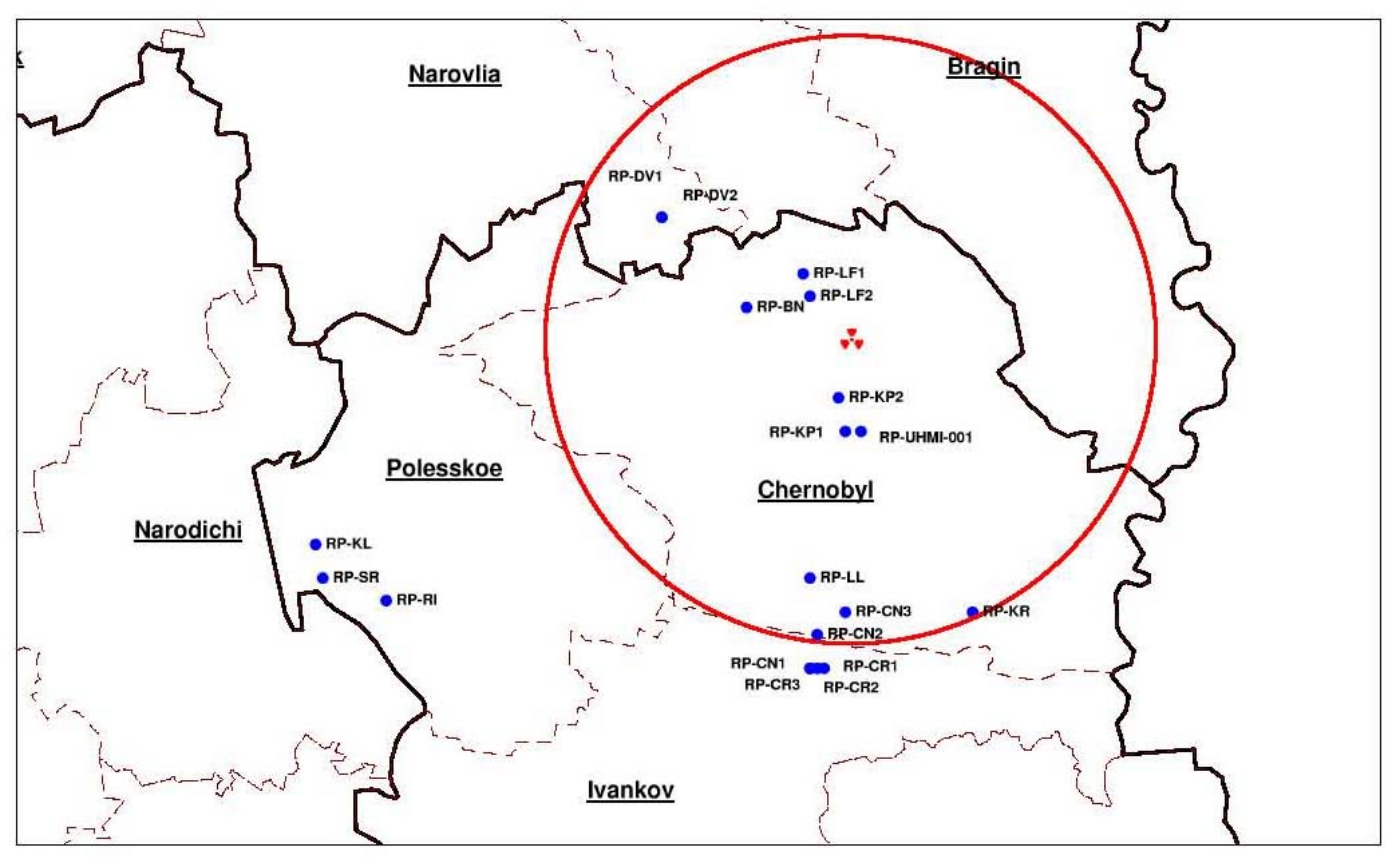

Figure 1. Location of the 19 sites concerned by the heavy rain experiments. Underlined words are the English names of the districts (raions). The circle is $30 \mathrm{~km}$ from Chernobyl nuclear power plant.

However, these transfer functions are not adapted for short term assessments. Radionuclide wash-off cannot be supposed invariant and continuous at fine time scales. Studies on small plots show great variability in removal rates between rainfalls [5]. In some cases, just few rainfalls lead to the most important inventory losses of a whole season [1, 6]. Wash-off transfer factors at fine time scales need thus better reporting and understanding.

This work aimed at treating the new database on ${ }^{137} \mathrm{Cs}$ and ${ }^{90} \mathrm{Sr}$ transfer by wash-off collected by IRSN in the framework of the Franco-German Initiative for Chernobyl (FGI). These data, mostly still unpublished, provide a quantification of wash-off at the rainfall scale, still rare for radionuclides.

\section{THE HEAVY RAIN EXPERIMENTS}

After the Chernobyl accident, experiments were conducted on contaminated plots in the neighbouring regions of the power plant (Fig. 1). Some of them consisted in applying artificial rainfalls on delimited plots. They were called heavy rain experiments. During each experiment, the operators were monitoring water fluxes (rainfall intensity and runoff flow rate at the outlet). They were also gathering runoff samples to later analyse their concentration in ${ }^{137} \mathrm{Cs}$ and ${ }^{90} \mathrm{Sr}$ in water and suspended matter. Generally, the initial soil contamination was measured by collecting soil samples near the experimental plots.

Altogether 71 heavy rain experiments were done from 1986 to 1998 on 19 sites in the districts (raions) of Chernobyl, Polesskoe, Ivankov and Narovlia. The plots were from 1 (63 experiments) to $750 \mathrm{~m}^{2}$ wide, and had a mean slope ranging from 0.5 to $19.1 \%$.

During the FGI project, all the data concerning these experiments were gathered in a specific database. Besides the wash-off measures, some tables also contain numerous co-variables for a better interpretation of the observed processes. Amongst other, the sites and experiments are described by the plot size and slope; soil type, texture and cover; experiment date and time. 


\section{ANALYSIS}

Soluble and participate fluxes of ${ }^{137} \mathrm{Cs}$ and ${ }^{90} \mathrm{Sr}$ were quantified at the rainfall scale by normalized entrainment coefficients $K_{1}^{*}$ and $K_{\mathrm{s}}^{*}$. They quantify the effeciency of the vectors of contamination. Their values correspond to the fraction of the initial soil contamination washed-off by, respectively, $1 \mathrm{~mm}$ of water and $1 \mathrm{~g} / \mathrm{m}^{2}$ of suspended matter.

Normalized entrainment coefficient are real transfer factors. They are defined as the ratio of the weighted-mean concentration in soluble or particulate runoff $(\mathrm{Bq} / 1$ of water or $\mathrm{Bq} / \mathrm{g}$ of suspended matter) and mean plot contamination density $\left(\mathrm{Bq} / \mathrm{m}^{2}\right)$ [7]. Using the name conventions of Fig. 2, liquid $K_{1}^{*}$ and solid $K_{s}^{*}$ entrainment coefficients have the following expressions:

$$
\begin{aligned}
K^{*}(M) & =\frac{\int_{0}^{T}[M]_{\text {wat }}(t) Q_{\text {wat }}(t) d t}{\int_{0}^{T} Q_{\text {wat }}(t) d t} \times \frac{S}{\int_{S}[M]_{\text {soil }}(S) d s} \\
K^{*} & (M)=\frac{\int_{0}^{T}[M]_{\mathrm{SM}}(t) Q_{\mathrm{SM}}(t) d t}{\int_{0}^{T} Q_{\mathrm{SM}}(t) d t} \times \frac{S}{\int_{S}[M]_{\text {soil }}(S) d s}
\end{aligned}
$$

Equations 3.1 and 3.2 are not directly applicable because, in practice, the measured variables are not continuous in space or time. Adopted solutions have not been detailed in the literature [7, 8]. Here we made the following choices: The mean contamination density was derived from soil contaminations profiles, when available. Contamination density was estimated by the mean total contamination of the sampled layers. The measured time series (flux, concentration) were completed with a 1-minute time step interpolation/extrapolation algorithm. Each measure was supposed valid till the next one or the end of the experiment. The time integrals could then be decomposed into sums.

The data were processed with ad hoc routines written with the S-plus programming language (1988-2000, MathSoft Inc., Seattle). Notably, the routines allow an automatic treatment of tables with varying size. Moreover, their outputs can be easily updated if the database and analyses are to evolve.

\section{RESULTS}

Only 20 experiments could not be analysed because of missing data series. The entrainment coefficients for the other 51 experiments are given in Tab. 1.

A quality index was introduced to judge globally the information associated to each experiment. It was defined so that a value of 100 indicates an accurate coefficient. This index is numerically defined by the product of data sampling rate (expressed in data per 3 minutes for runoff flux and concentrations) and the portion of the series that coincide (lower values than $100 \%$ indicate that extrapolation had to be made).

The quality index must be used to weigh the entrainment coefficient. Indeed, the experiments (7) with a null index cannot be interpreted because they rely on pure extrapolations. Those with low indexes (41) certainly underestimate wash-off because either runoff or concentration was not measured at the begin of the experiments. The experiments with high indexes (3) yield accurate calculations. They show that runoff rate and concentrations vary significantly as a function of time (Fig. 3).

Mean and standard deviation were estimated for all the calculated entrainment coefficients (Tab. 2). These statistics were determined after weighing the coefficients by their quality index. For all 


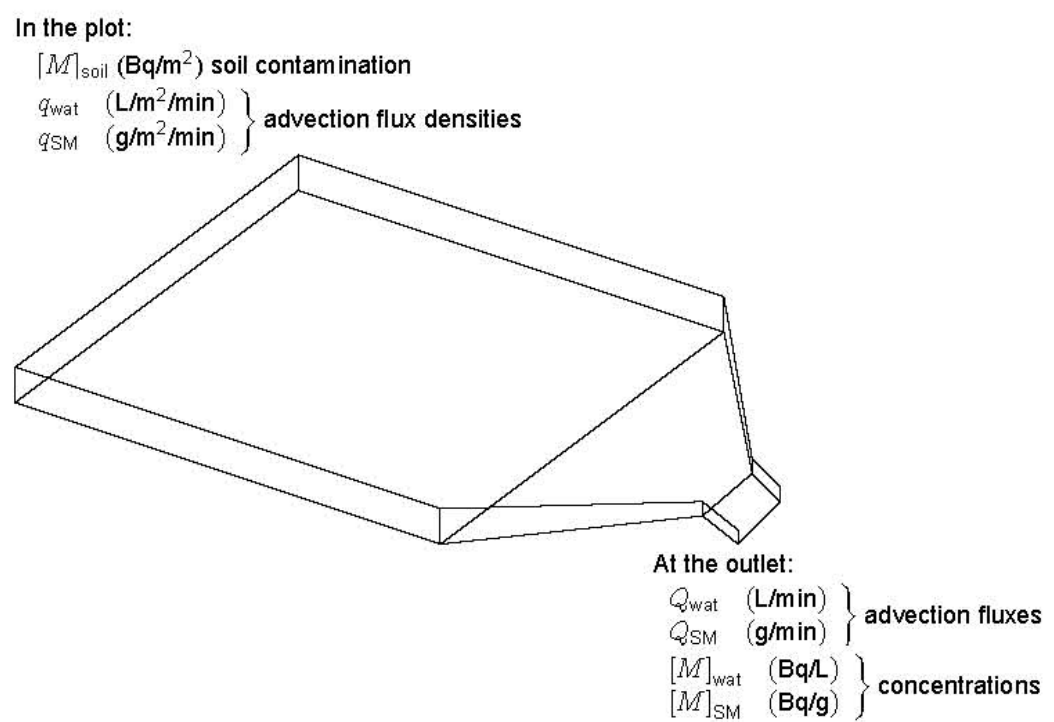

Figure 2. Name conventions for the variables associated to the heavy rain experiments. The radionuclide (M) is here either ${ }^{137} \mathrm{Cs}$ or ${ }^{90} \mathrm{Sr}$. The subscripts wat and SM refer to water and suspended matter. Fluxes were only monitored at the outlet of the whole plot surface (S), from time 0 to $\mathrm{T}$.
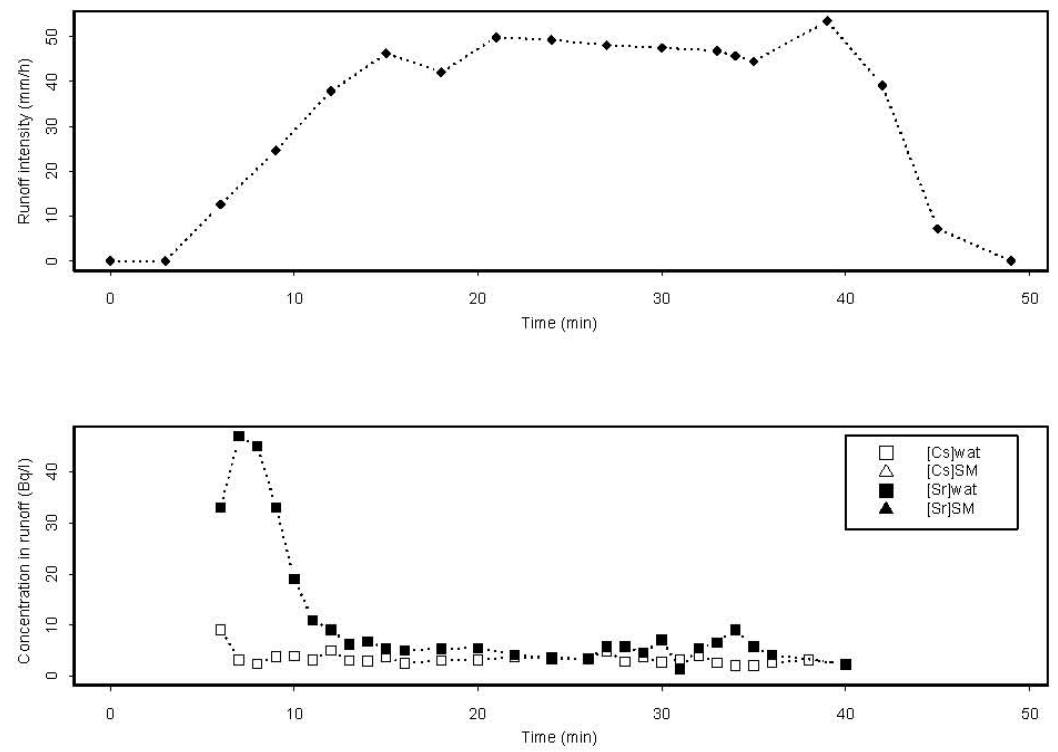

Figure 3. Measured runoff rate $(\mathrm{mm} / \mathrm{h})$ and concentrations $(\mathrm{Bq} / 1)$ during the experiment HR-BN-91. Time (min) is counted from the begin of the experiment.

the experiments, the coefficients span one order of magnitude about their mean. For liquid wash-off, ${ }^{90} \mathrm{Sr}$ was significantly more mobilized than ${ }^{137} \mathrm{Cs}$, of about one order of magnitude. For solid wash-off, ${ }^{137} \mathrm{Cs}$ was a little more removed by erosion than ${ }^{90} \mathrm{Sr}$. 
Table 1. Normalized entrainment coefficients $K^{*}{ }_{1}\left(\mathrm{~mm}^{-1}\right)$ and $K^{*}{ }_{s}\left(\mathrm{ra}^{2} \mathrm{~g}^{-1}\right)$ for the heavy rain experiments. The quality index is a global measure of completeness of the data series (see text).

\begin{tabular}{|c|c|c|c|c|c|}
\hline Experiment & $K_{1}^{*}\left({ }^{137} \mathrm{Cs}\right)$ & $K^{*}{ }_{1}\left({ }^{90} \mathrm{Sr}\right)$ & $K_{\mathrm{s}}^{*}\left({ }^{137} \mathrm{Cs}\right)$ & $K_{\mathrm{s}}^{*}\left({ }^{90} \mathrm{Sr}\right)$ & quality \\
\hline HR-BN-86/1 & $2.8610^{-6}$ & $2.9910^{-5}$ & $3.7510^{-5}$ & & 33 \\
\hline HR-BN-86/2 & $3.2710^{-6}$ & $3.4010^{-5}$ & $1.1410^{-4}$ & $7.3010^{-5}$ & 69 \\
\hline HR-BN-86/3 & $9.5810^{-6}$ & $1.1910^{-4}$ & $4.4310^{-5}$ & $2.7310^{-5}$ & 124 \\
\hline HR-BN-87/1 & $1.4810^{-6}$ & $2.3310^{-4}$ & $8.6710^{-5}$ & & 76 \\
\hline HR-BN-87/2 & $1.3210^{-6}$ & $1.9310^{-4}$ & $1.0610^{-4}$ & & 68 \\
\hline HR-BN-88/1 & $8.6010^{-6}$ & $1.9310^{-4}$ & $2.8110^{-4}$ & & 53 \\
\hline HR-BN-88/2 & $4.5410^{-6}$ & $1.0310^{-4}$ & $1.1410^{-4}$ & & 34 \\
\hline HR-BN-88/3 & $5.9210^{-6}$ & & $8.4410^{-5}$ & & 36 \\
\hline HR-BN-88/4 & $6.9210^{-6}$ & $1.4210^{-4}$ & $4.9910^{-5}$ & & 87 \\
\hline HR-BN-91 & $2.5910^{-6}$ & & $4.5510^{-5}$ & & 249 \\
\hline HR-CN1-86 & $1.0310^{-4}$ & $2.7910^{-4}$ & $6.9810^{-4}$ & $3.1110^{-4}$ & 20 \\
\hline HR-CN2-86 & $4.6010^{-5}$ & $2.5910^{-4}$ & $1.4210^{-4}$ & $4.9810^{-5}$ & 44 \\
\hline HR-CN3-89/1 & $6.7810^{-6}$ & $3.8410^{-4}$ & & & 33 \\
\hline HR-CN3-89/2 & $6.1010^{-6}$ & $4.0310^{-4}$ & & & 36 \\
\hline HR-CN3-89/3 & $7.2910^{-6}$ & $3.7610^{-4}$ & & & 55 \\
\hline HR-CN3-89/4 & $6.3110^{-6}$ & $3.4010^{-4}$ & & & 63 \\
\hline HR-CN3-91 & $7.4410^{-6}$ & & $1.0310^{-4}$ & & 11 \\
\hline HR-CR1-86 & $2.1710^{-4}$ & $8.6610^{-5}$ & $7.9010^{-5}$ & $4.4510^{-5}$ & 70 \\
\hline HR-CR2-86 & $3.7610^{-5}$ & $1.4410^{-4}$ & $2.2510^{-4}$ & $1.3310^{-4}$ & 66 \\
\hline HR-CR3-86 & $6.3110^{-5}$ & $6.2510^{-4}$ & $1.8310^{-4}$ & $2.4210^{-4}$ & 62 \\
\hline HR-DV1-86/1 & $1.4210^{-5}$ & $9.8510^{-5}$ & $3.8510^{-4}$ & $7.6710^{-4}$ & 0 \\
\hline HR-DV1-86/4 & $3.5210^{-5}$ & $1.4110^{-4}$ & $6.5010^{-4}$ & $2.2410^{-4}$ & 41 \\
\hline HR-DV1-86/7 & $8.5410^{-6}$ & $2.9410^{-5}$ & $2.7810^{-5}$ & $1.1910^{-5}$ & 130 \\
\hline HR-DV1-86/8 & $4.1410^{-6}$ & $2.6010^{-5}$ & $4.9310^{-5}$ & $6.3410^{-5}$ & 28 \\
\hline HR-DV1-87 & $1.2810^{-6}$ & $1.3410^{-5}$ & $4.5810^{-5}$ & $3.8210^{-5}$ & 13 \\
\hline HR-DV2-86/2 & $5.2310^{-5}$ & $1.0310^{-4}$ & $1.0810^{-4}$ & $8.8610^{-5}$ & 40 \\
\hline HR-DV2-86/3 & $3.1810^{-5}$ & $1.0310^{-4}$ & $1.6310^{-4}$ & $5.2910^{-5}$ & 36 \\
\hline HR-KL-89 & & $2.0110^{-4}$ & $2.8010^{-4}$ & & 37 \\
\hline HR-KP2-87/2 & $2.9510^{-7}$ & $6.6110^{-6}$ & $7.7710^{-6}$ & $3.9010^{-6}$ & 0 \\
\hline HR-KP2-87/4 & $4.8510^{-8}$ & $2.9210^{-6}$ & $6.7610^{-6}$ & $9.4610^{-6}$ & 0 \\
\hline HR-KP2-88/1 & $8.0710^{-6}$ & $1.0410^{-4}$ & $2.4510^{-5}$ & & 29 \\
\hline HR-KP2-88/3 & $5.3810^{-6}$ & $1.2010^{-4}$ & $5.3710^{-5}$ & & 37 \\
\hline HR-KP2-91 & $1.3210^{-5}$ & & $2.9210^{-5}$ & & 88 \\
\hline HR-KR-87 & $3.0010^{-6}$ & $9.2010^{-5}$ & $1.5710^{-4}$ & $9.6510^{-5}$ & 18 \\
\hline HR-KR-88/1 & $2.2710^{-6}$ & $1.0910^{-4}$ & $2.9310^{-5}$ & & 12 \\
\hline HR-KR-88/2 & $1.4810^{-5}$ & $6.4510^{-5}$ & $1.0610^{-4}$ & & 45 \\
\hline HR-KR-88/3 & $3.7010^{-5}$ & $7.3010^{-5}$ & $2.9510^{-5}$ & & 23 \\
\hline HR-KR-89/2 & $7.2410^{-6}$ & $1.9810^{-4}$ & $6.7210^{-5}$ & & 33 \\
\hline HR-KR-90/1 & & $5.6010^{-4}$ & & & 45 \\
\hline HR-KR-90/2 & & $4.7410^{-4}$ & & & 67 \\
\hline HR-LF1-91 & $2.9710^{-5}$ & $3.3710^{-5}$ & $5.5210^{-6}$ & & 5 \\
\hline HR-LF2-91 & $6.8910^{-6}$ & $1.4810^{-5}$ & & & 0 \\
\hline HR-LL-89/1 & $2.5310^{-5}$ & $2.9210^{-4}$ & $3.0110^{-4}$ & & 49 \\
\hline HR-LL-89/2 & $1.5810^{-5}$ & $2.4510^{-4}$ & $3.4010^{-4}$ & & 69 \\
\hline HR-RI-88 & $3.7710^{-5}$ & & $2.1910^{-4}$ & & 36 \\
\hline HR-RI-89/1 & $1.8210^{-5}$ & & $5.7610^{-5}$ & & 42 \\
\hline HR-RI-89/2 & & & $4.1310^{-4}$ & & 45 \\
\hline HR-RI-89/3 & & $3.3810^{-4}$ & $7.4710^{-4}$ & & 14 \\
\hline HR-RI-89/4 & & $3.9410^{-5}$ & $1.8110^{-3}$ & & 0 \\
\hline HR-SR-89/1 & & & $7.7910^{-4}$ & & 0 \\
\hline HR-SR-89/2 & & & $7.1910^{-5}$ & & 0 \\
\hline
\end{tabular}

Table 2. Weighted mean and standard deviation of the log-transformed entrainment coefficients (K).

\begin{tabular}{lcccc} 
coefficient $(K)$ & $\hat{\mu}\left[\log _{10}(K)\right]$ & \multicolumn{3}{c}{$\hat{\sigma}\left[\log _{10}(K)\right]$} \\
\hline $\mathrm{K}^{*}{ }_{1}\left({ }^{137} \mathrm{Cs}\right) \mathrm{mm}^{-1}$ & $-5,0$ & \pm & 0,5 & $(\mathrm{n}=39)$ \\
$\mathrm{K}^{*}{ }_{1}\left({ }^{90} \mathrm{Sr}\right) \mathrm{mm}^{-1}$ & $-3,8$ & \pm & 0,4 & $(\mathrm{n}=37)$ \\
$\left.\mathrm{K}_{\mathrm{s}}{ }^{137} \mathrm{Cs}\right) \mathrm{m}^{2} / \mathrm{g}$ & $-4,1$ & \pm & 0,4 & $(\mathrm{n}=38)$ \\
$\left.\mathrm{K}_{\mathrm{s}}{ }^{9}{ }^{90} \mathrm{~Sv}\right) \mathrm{m}^{2} / \mathrm{g}$ & $-4,3$ & \pm & 0,4 & $(\mathrm{n}=14)$ \\
\hline
\end{tabular}




\section{DISCUSSION}

These trends and values are consistent with reported values in the literature. Higher liquid wash-off for ${ }^{90} \mathrm{Sr}$ than ${ }^{137} \mathrm{Cs}$ has been largely observed since the bombogenic fallout, e.g. [10].

Table 3. Order of magnitude of normalized entrainment coefficients reported in the literature $[7,8]$.

\begin{tabular}{lll} 
coefficient & Bulgakov et al. (1991) & Bulgakov et al. (1999) \\
\hline $\mathrm{K}^{*}{ }_{1}\left({ }^{137} \mathrm{Cs}\right) \mathrm{mm}^{-1}$ & $\sim 1.10^{-5}$ & $\sim 2.10^{-6}$ \\
$\left.\mathrm{~K}^{*}{ }_{1}{ }^{00} \mathrm{Sr}\right) \mathrm{mm}^{-1}$ & $\sim 1.10^{-4}$ & $\sim 3.10^{-5}$ \\
$\left.\mathrm{~K}_{\mathrm{s}}{ }^{137} \mathrm{Cs}\right) \mathrm{m}^{2} / \mathrm{g}$ & & $\sim 1.10^{-4}$ \\
$\left.\mathrm{~K}_{\mathrm{s}}{ }^{90} \mathrm{Sr}\right) \mathrm{m}^{2} / \mathrm{g}$ & & $\sim 5.10^{-5}$ \\
\hline
\end{tabular}

Calculated values are in agreement with the few coefficients already reported for similar experiments around Chernobyl (Tab. 3).

This database completes significantly the available information on radionuclide wash-off at the rainfall scale. In quantity, the number of experiments reported has no equivalent in the literature. Indeed, the existing data concern a very limited number of sites $[1,5,6,10]$. In quality, its content, though not perfect, is much more homogeneous and detailed than anywhere else. The contamination was monitored at the rainfall scale with a few minutes time step, whereas the literature mainly contains rough estimations of yearly fluxes. Soluble and particulate fluxes were distinguished whereas the literature generally focuses on soluble species. The advection fluxes (liquid and solid runoff rates) were also measured, whereas they are generally omitted or considered at steady state.

\section{CONCLUSIONS}

This paper contains wash-off transfer factors derived from the "Runoff' FGI database. They could be derived from 51 out of the 71 wash-off experiments conducted around Chernobyl. This database represents by far the largest amount of existing empirical data on wash-off. For assessment purposes, the extrapolation of these coefficients to wider areas and to other sites would need their physical interpretation.

\section{References}

[1] Menzel, R. Transport of strontium-90 in runoff. Science 131 (1960) 499-500.

[2] Jacobi, W. Transfer of fission products from atmospheric fallout into river water. Radioecology applied to the protection of man and its environment (Commission of the European Communities, Luxembourg, 1971), pp.1153-1165

[3] Monte, L. Evaluation of radionuclide transfer functions from drainage basins of freshwater systems. J. Environ. Radioactivity 26 (1995) 71-82.

[4] Smith, J.T., Clarke, R. and Saxn, R. Time-dependent behaviour of radioceasium: A new method to compare mobility of weapon test and Chernobyl derived fallout. J. Environ. Radioactivity 49 (2000) 65-83.

[5] Helton, J., Muller, A. and Bayer, A. Contamination of surface water bodies after reactor accidents by the erosion of atmospherically deposited radionuclides. Health Phys. 48 (1985) 757-771.

[6] Rogowski, A. and Tamura, T. Environmental mobility of cesium-137. Radiation Botany 10 (1970) 35-45.

[7] Bulgakov, A., Konoplev, A., Popov, V. and Scherbak, A. Removal of long-lived radionuclides from the soil by surface runoff near the Chernobyl nuclear power plant. Soviet Soil Science 23 (1991) 124-131.

[8] Bulgakov, A., Konoplev, A., Schveikin, Yu.V. and Scherbak, A. Experimental study and prediction of dissolved radionuclide wash-off by surface runoff from non-agricultural watersheds. Linkov and Schell Eds, Contaminated Forests (Kluwer Academic Publishers, 1999) pp.103-112.

[9] Linsley, G., Haywood, S. and Dionan, J. Use of fall-out data in the development of models for the transfer of nuclides in terrestrial and freshwater systems. R eport SM-257 (IAEA, Vienna, 1982), pp.615-633.

[10] Khanbilvardi, R., Shestopalov, V., Onishchenko, I., Bublyas, V., Gudzenko, V. Role of erosion processes in transfer of radionuclides: results of field experiments. J. Amer. Wat. Resour. Asso. 35 (1999) 887-898. 